\title{
Dissociation of absorptions of calcium and phosphate after successful cadaveric renal transplantation
}

\author{
K FARRINGTON, Z VARGHESE, S P NEWMAN, K Y AHMED, \\ O N FERNANDO, J F MOORHEAD
}

British Medical Fournal, 1979, 1, 712-714

\section{Summary and conclusions}

Calcium and phosphate absorptions were studied by radiotracer techniques in 30 patients after successful cadaveric renal transplantation, and results were compared with those in a group of normal subjects and in groups of patients with chronic renal failure (CRF). Both calcium and phosphate absorptions were impaired in patients with CRF, including those receiving haemodialysis. Abnormalities of calcium absorption, however, seemed to occur earlier in the course of advanced renal failure than abnormalities in phosphate absorption. Calcium absorption improved dramatically after successful renal transplantation, while phosphate absorption remained the same.

A dissociation between calcium and phosphate absorptions is not often seen clinically, and the mechanisms for it are unknown. Phosphate malabsorption may be a further contributing factor in the development of persistent hypophosphataemia after transplantation.

\section{Introduction}

Hypophosphataemia is now considered to be common after renal transplantation and has been attributed in established patients with stable renal function to a renal phosphate leak. ${ }^{2}$ We devised this study to assess the possible contribution of phosphate malabsorption to hypophosphataemia occurring after transplantation. We compared the combined measurements of calcium and phosphate absorptions obtained by radiotracer techniques in patients who had received transplants with those obtained in patients with chronic renal failure (CRF) treated by diet or maintained on regular haemodialysis, and in controls.

\footnotetext{
Department of Nephrology and Transplantation, Royal Free Hospital, London NW3 2QG

K FARRINGTON, BSC, MRCP, research fellow

Z VARGHESE, MSC, principal biochemist

K Y AHMED, DM, research fellow (present appointment: senior resident, King Faisal Hospital, Riyadh, Saudi Arabia)

O N FERNANDO, FRCs, consultant surgeon

J F MOORHEAD, FRCP, director

Medical Physics Department, Royal Free Hospital

S P NEWMAN, MSC, physicist
}

\section{Subjects and methods}

We studied 116 subjects-namely, 30 patients who had received cadaveric renal transplants and in whom these had been functioning for over three months; 20 patients with stable CRF maintained with diet; 46 patients with CRF who were receiving regular haemodialysis; and 20 normal controls. The table shows the clinical and biochemical details of these patients and controls. All of the transplant recipients were receiving standard immunosuppressive treatment with prednisolone and azathioprine, and some were receiving phosphate supplements. In addition some patients were receiving antihypertensive drugs and frusemide. All of the patients with CRF were receiving aluminium hydroxide, but none were taking vitamin $\mathrm{D}$ compounds.

Calcium and phosphate absorption test ${ }^{3}$-Oral doses of $5 \mu \mathrm{Ci}{ }^{45} \mathrm{Ca}$ with $20 \mathrm{mg}$ calcium carrier and $5 \mu \mathrm{Ci}{ }^{32} \mathrm{P}$ with $50 \mathrm{mg}$ of phosphate carrier in $250 \mathrm{ml}$ of dilute orange squash were administered simultaneously to all patients and controls over 40 years of age. Controls aged under 40 received $5 \mu \mathrm{Ci}^{47} \mathrm{Ca}$ and $5 \mu \mathrm{Ci}{ }^{32} \mathrm{P}$ with carrier amounts of both substances on separate occasions. Plasma samples were collected at $0,15,30,60,90,120$, and 180 minutes, and the activities of ${ }^{32} \mathrm{P}$ and ${ }^{45} \mathrm{Ca}$ were assayed in each sample by liquid scintillation counting. The fractional rates of absorption for calcium $(\alpha \mathrm{Ca})$ and phosphate $\left(\alpha \mathrm{PO}_{4}\right)$ were then calculated. ${ }^{4}$ Before the test all subjects were maintained on a standard calcium diet of $800 \mathrm{mg} /$ day for five days; in the case of all the patients with CRF this entailed supplementing the diet with oral calcium carbonate. The controls and patients who had undergone transplantation received a standard phosphate diet of $1000 \mathrm{mg} / 24$ hours for five days before testing. The daily phosphate intake of all the patients with CRF was $600-800 \mathrm{mg}$. Aluminium hydroxide was discontinued 48 hours before testing and phosphate supplements at least two weeks beforehand. The tests were begun at 9 am after a 10 -hour fast. They were carried out on the patients receiving haemodialysis at least 36 hours after the last dialysis.

Biochemical analysis-Plasma and urinary creatinine, plasma calcium, plasma phosphate, and alkaline phosphate concentrations were measured by standard methods.

\section{Results}

The four groups showed the expected differences in biochemical results (table). The plasma calcium concentration in the transplant recipients did not differ significantly from that in the controls, though it was higher in the patients receiving haemodialysis $(P<0.001)$ and lower in those with CRF treated with diet $(P<0.02)$. The plasma phosphate concentration was low in the patients who had received transplants $(P<0.001)$ and raised in the two groups of patients with CRF $(P<0.001)$. Creatinine clearance was significantly lower in transplant recipients compared with controls $(P<0.001)$.

Figure 1 shows the mean experimental curves. The calcium control curve peaked at 90 minutes and the phosphate control curve at 60 minutes. The curves obtained in the patients who had received transplants closely resembled the control curves in this respect. In the curves for the two groups of patients with CRF peak values were coincident with those of the control curves or slightly delayed, though

Mean $( \pm S D)$ clinical and biochemical details of subjects studied

\begin{tabular}{|c|c|c|c|c|c|c|c|}
\hline Group & $\begin{array}{l}\text { No in } \\
\text { group }\end{array}$ & $\underset{(\text { years) }}{\text { Age }}$ & $\begin{array}{c}\text { Creatinine } \\
\text { clearance } \\
(\mathrm{ml} / \mathrm{min})\end{array}$ & $\begin{array}{c}\begin{array}{c}\text { Duration of } \\
\text { transplant or dialysis } \\
\text { (months) }\end{array} \\
\text { (mons }\end{array}$ & $\begin{array}{c}\text { Plasma } \\
\text { calcium } \\
(\mathrm{mmol} / \mathrm{l})\end{array}$ & $\underset{\substack{\text { phosphate } \\
(\mathrm{mmol} / \mathrm{l})}}{\text { Plasma }}$ & $\begin{array}{c}\text { Alkaline } \\
\text { phosphate } \\
\text { (KA units) }\end{array}$ \\
\hline $\begin{array}{l}\text { Transplant recipients } \\
\text { CRF } \\
\text { Regular haemodialysis } \\
\text { Controls }\end{array}$ & $\begin{array}{l}30 \\
20 \\
46 \\
20\end{array}$ & $\begin{array}{l}41 \cdot 7 \pm 10 \cdot 7 \\
39 \cdot 1 \pm 15 \cdot 3 \\
36 \cdot 9 \pm 13 \cdot 3 \\
36 \cdot 4 \pm 11 \cdot 1\end{array}$ & $\begin{array}{c}80 \cdot 3 \pm 21 \cdot 7 \\
10 \cdot 5 \pm 5 \cdot 8 \\
112 \cdot 4 \pm 11 \cdot 1\end{array}$ & $\begin{array}{l}30 \cdot 6 \pm 27 \cdot 3 \\
65 \cdot 4 \pm 44 \cdot 7\end{array}$ & $\begin{array}{l}2 \cdot 54 \pm 0 \cdot 19 \\
2 \cdot 39 \pm 0 \cdot 16 \\
2 \cdot 66 \pm 0 \cdot 21 \\
2 \cdot 50 \pm 0 \cdot 07\end{array}$ & $\begin{array}{l}0.82 \pm 0.15 \\
1.73 \pm 0.43 \\
1.75 \pm 0.56 \\
1.06 \pm 0.19\end{array}$ & $\begin{aligned} & 8 \cdot 0 \pm 4 \cdot 6 \\
& 15 \cdot 3 \pm 17 \cdot 1 \\
& 23 \cdot 8 \pm 21 \cdot 3 \\
& 8 \cdot 6 \pm 3 \cdot 1\end{aligned}$ \\
\hline
\end{tabular}

Conversion: SI to traditional units-Plasma calcium: $1 \mathrm{mmol} / 1 \approx 4 \mathrm{mg} / 100 \mathrm{ml}$. Plasma phosphate $\approx 3.1 \mathrm{mg} / 100 \mathrm{ml}$. 


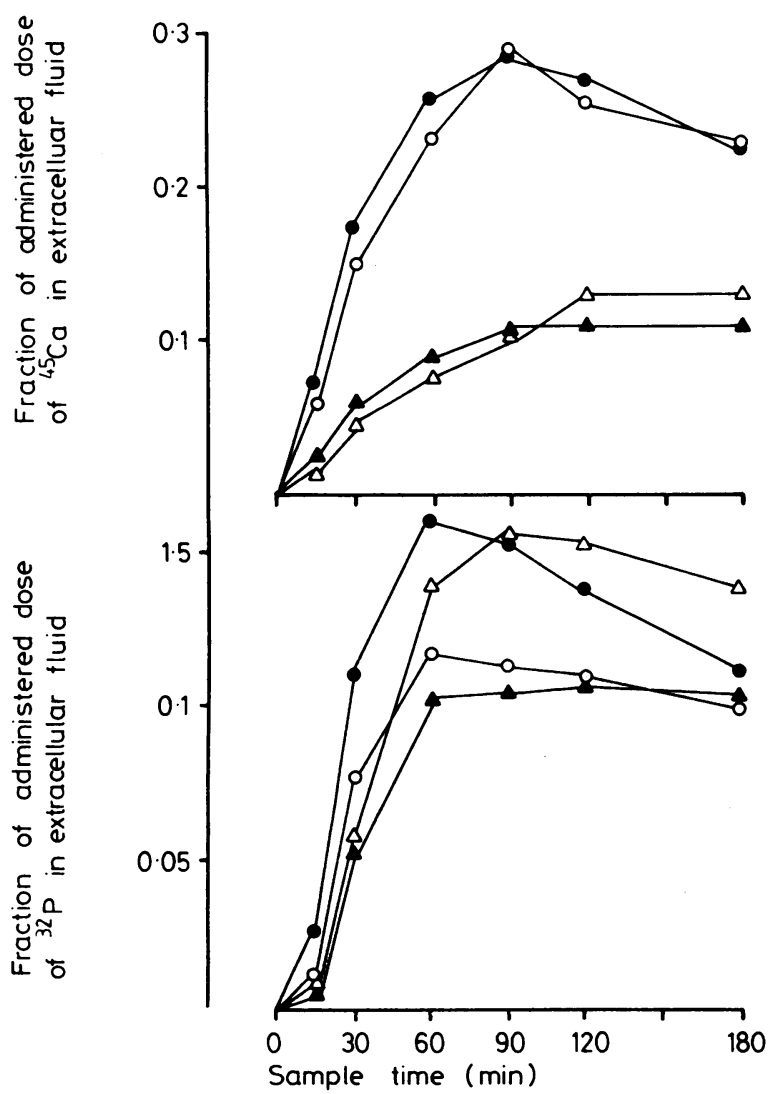

FIG 1-Plasma activity of calcium and phosphate during threehour absorption tests in the four groups studied.

- Controls. $O=$ Patients who had received transplants. $\Delta=$ Patients receiving haemodialysis. $\triangle=$ Patients with CRF.

for both calcium and phosphate absorption the curves had reached a peak or a plateau well before the final three-hour sample.

In all patients and controls $\alpha \mathrm{Ca}$ and $\alpha \mathrm{PO}_{4}$ were significantly correlated with the plasma concentrations of, respectively, radioactive calcium and phosphate obtained at 30,60 , and 90 minutes. The highest correlations were between $\alpha \mathrm{Ca}$ and the 60 -minute plasma concentration $(r=0.95, P<0.001)$, and between $\alpha \mathrm{PO}_{4}$ and the 30minute plasma concentration $(r=0.89, P<0.001) . \alpha C a$ was also significantly correlated with $\alpha \mathrm{PO}_{4}(\mathrm{r}=0.34, \mathrm{P}<0.001)$ and with creatinine clearance $(r=0.55, P<0.001)$. Figure 2 shows the mean values of $\alpha \mathrm{Ca}$ and $\alpha \mathrm{PO}_{4}$ in each group. In both groups of patients with $\mathrm{CRF} \alpha \mathrm{Ca}$ was significantly lower than that in controls $(\mathrm{P}<0.001$ in both cases). In the transplant recipients, however, $\alpha \mathrm{Ca}$ was not significantly different from that in controls, though the mean value was slightly lower. Patients with CRF treated by diet had a lower mean value of $\alpha \mathrm{PO}_{4}$ than controls, though this barely attained significance

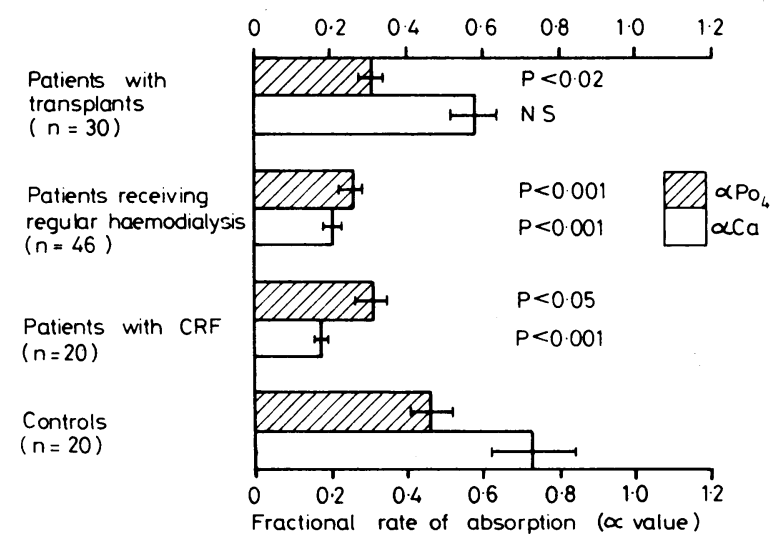

FIG 2-Mean fractional rates of absorption in the four groups studied. Ranges indicate SE of mean.
$(\mathrm{P}<0.05)$. In patients receiving regular haemodialysis $\alpha \mathrm{PO}_{4}$ was also low, the difference from control values being highly significant $(\mathrm{P}<0.001) . \alpha \mathrm{PO}_{4}$, unlike $\alpha \mathrm{Ca}$, failed to improve after transplantation and remained significantly lower in transplant recipients than controls $(\mathrm{P}<0.02)$.

In order to study the possible contribution of phosphate malabsorption to the development of persistent hypophosphataemia after transplantation, we subdivided 20 patients with renal allografts that had been functioning for over one year (mean 43.2 months) into hypophosphataemic and normophosphataemic groups according to serial plasma phosphate concentrations over the previous six months. Figure 3 shows the results of phosphate absorption tests in these two groups. The mean value of $\alpha \mathrm{PO}_{4}$ in the hypophosphataemic group was lower than that in the normophosphataemic group, though not significantly so. The groups did not differ significantly with respect to age, longevity of transplant, creatinine clearance, or steroid dose.
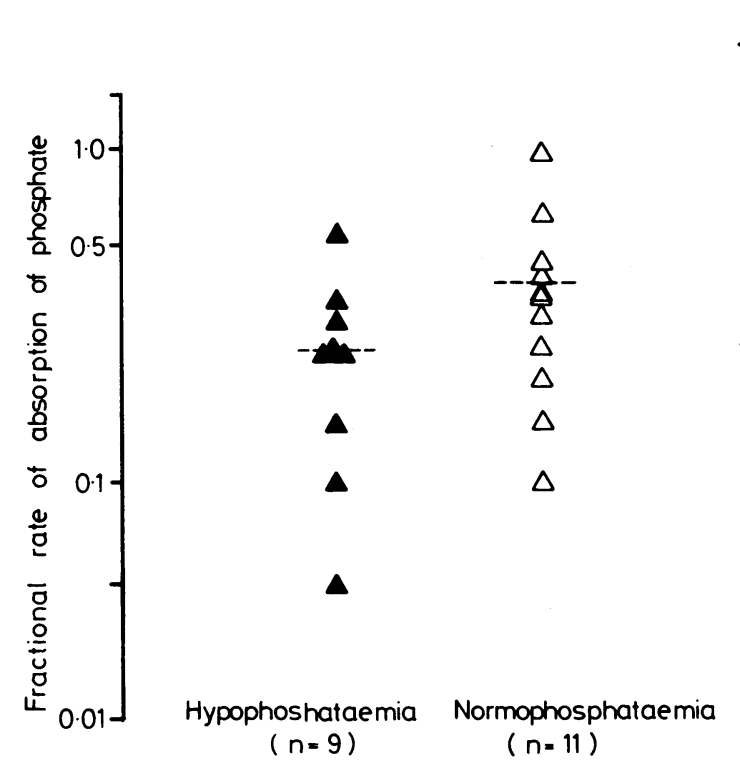

FIG 3-Fractional rates of absorption of phosphate in patients with hypophosphataemia and normophosphataemia who had undergone transplantation.

\section{Discussion}

Marshall showed that $\alpha \mathrm{Ca}$ and $\alpha \mathrm{PO}_{4}$ as measured by this technique agree well with values obtained from balance studies. ${ }^{4}$ We confirmed the correlation between $\alpha \mathrm{Ca}$ and $\alpha \mathrm{PO}_{4}{ }^{4}$ and also found the expected dependence of calcium absorption on renal function. Theoretical limitations exist, however, when this combined technique is used. If both calcium and phosphate absorption continue beyond the studied period of three hours, then delayed absorption might be misinterpreted as malabsorption. The shapes of the experimental plasma activity curves (fig 1), however, provide little evidence for delayed absorption. Furthermore, for calcium absorption at least, the first two hours are optimal for detecting impairments of the active components of absorption. ${ }^{5}$

The shapes of the experimental curves are also likely to be affected by several factors other than the rate of intestinal absorption. These include the quantity of carrier material used, the rate of gastric emptying, the intestinal transit time, the rate of tissue uptake, and the rate of renal loss of the absorbed substances. Evidence also exists that intraluminal phosphate may be incorporated into mucosal-cell phospholipids, which would introduce further difficulties in standardisation. ${ }^{6}$ ? Of these factors, the only one that may be standardised is the quantity of carrier material. Only $1-2 \%$ of both radioisotopes, however, are excreted in the urine in the first 24 hours, and hence renal excretion would not appear to be an important factor. Increased tissue avidity for calcium and phosphate in the groups studied could cause flattening of the plasma activity curves. If plasma clearance of calcium and phosphate were increased to such an 
extent by any mechanism, however, more rapid attainment of peak plasma activity might also be expected, and this was not observed. This suggests that the major differences between the plasma activity curves in the groups studied cannot be accounted for by increased plasma clearance of calcium and phosphate. Within the remaining limitations described above we may reasonably assume that the fractional rates of absorption ( $\alpha$ values) calculated from these curves are valid as an index of absorption.

Coburn et al showed that calcium absorption is reduced in patients with CRF, remains low after the institution of maintenance haemodialysis, and improves to normal values after renal transplantation. ${ }^{8}$ Our results fully accord with these. Impaired phosphate absorption in patients with CRF has been reported. ${ }^{9}$ We found that $\alpha \mathrm{PO}_{4}$ was minimally impaired in these patients. Examination of the plasma activity curves of calcium and phosphate (fig 1), however, suggests that abnormalities of calcium absorption occur earlier in the course of advanced renal failure than abnormalities in phosphate absorption. Few data are available on phosphate absorption in patients receiving haemodialysis $^{310}$ or after renal transplantation. Our results indicate that phosphate absorption remains inappropriately low after transplantation, despite good renal function, and that calcium and phosphate absorptions become dissociated. This dissociation appears to be maximal in those patients who are persistently hypophosphataemic.

Preliminary studies in our patients ${ }^{11} 12$ indicate normal concentrations of 25-hydroxycholecalciferol and 1,25-dihydroxycholecalciferol in patients with hypophosphataemia after transplantation, and the finding of phosphate malabsorption in this context is surprising. The interaction of various drugs with intestinal transport mechanisms for phosphate could be an important factor in this, and long-term steroid administration and cyclophosphamide treatment reduce phosphate absorption. ${ }^{13}$ There are, however, no published data on the effects of azathioprine. The net absorption of phosphate from perfused rat gut loops is increased by decreasing hydrogen ion concentrations. ${ }^{14}$ Thus the increased secretion of gastric acid produced by prednisolone $\mathrm{e}^{15}$ may possibly have a role in reducing phosphate absorption in transplant recipients. The systematic hyperchloraemic acidosis seen in these patients ${ }^{2}$ could contribute.

The dissociation in recovery from calcium and phosphate malabsorption after successful renal transplantation and the apparent earlier deterioration of calcium compared with phosphate absorption with declining renal function might also imply that the regulation of phosphate absorption is quite distinct from that of calcium absorption, as suggested. ${ }^{16}$ The differential responses of calcium and phosphate absorption to treatment with vitamin $D, 1-\alpha$-hydroxycholecalciferol, and 1,25-dihydroxycholecalciferol ${ }^{31017}$ may also suggest separate regulatory mechanisms of calcium and phosphate absorption.

In clinical terms, phosphate malabsorption after renal transplantation may be an important additional factor contributing to hypophosphataemia occurring after transplantation. ${ }^{2}$ Treating such hypophosphataemia with phosphate supplements alone may not be adequate in the presence of phosphate malabsorption, and the effect of treatment with vitamin D analogues or metabolites requires consideration.

We should like to thank Dr D H Marshall for his help.

\section{References}

1 Nielsen, $\mathrm{H} \mathrm{E}$, et al, Advances in Experimental Medicine and Biology, $1977,81,603$.

2 Moorhead, J F, et al, Lancet, 1974, 1, 694

3 Peacock, M, Davidson, A M, and Walker, G S, Advances in Experimental Medicine and Biology, 1977, 81, 559.

${ }_{4}^{4}$ Marshall, D H, in Calcium, phosphate and magnesium metabolism. Clinical physiology and diagnostic procedures, ed B E C Nordin, p 270 Edinburgh, Churchill Livingstone, 1976.

Brickman, A S, et al, Proceedings of the 5th International Congress of Nephrology, p 459. Basel, Karger, 1972.

6 Thompson, P W, and Deluca, H F, fournal of Biological Chemistry, 1964, 239, 984.

7 Wasserman, R H, and Taylor, A N, fournal of Nutrition, 1973, 103, 586.

${ }^{8}$ Coburn, J W, et al, Kidney International, 1973, 3, 264.

9 Stanbury, S W, and Lumb, G A, Medicine, 1962, 41, 1.

${ }^{10}$ Coburn, $\mathrm{J} \mathrm{W}$, et al, Advances in Experimental Medicine and Biology, 1977, 81, 549.

${ }^{11}$ Haussler, M R, personal communication, 1976.

12 Moorhead, J F, et al, in Vitamin $D$ and problems related to uraemic bone disease, ed A W Norman et al, p 310. New York, de Gruyter, 1975.

${ }^{13}$ Cannigia, A, and Gennari, C, in Phosphate et métabolisme phospho-calcique, ed D J Hioco, p 209. Paris, Expansion Scientifique Française, 1971.

${ }^{14}$ McHardy, G J R, and Parsons, D S, Quarterly fournal of Experimental Physiology, 1956, 41, 398.

15 Strickland, R G, Fisher, J M, and Taylor, K B, Gastroenterology, 1969, 156, 675 . Physiology, 1956, 41, 398.

${ }^{16}$ Norman, A W, in Vitamin D, ed D E M Lawson, p 93. London, Academic Press, 1978.

17 Stanbury, S W, in Inborn errors of calcium and bone metabolism, ed H Bickel and J Stern, p 21. Baltimore, University Park Press, 1976.

(Accepted 16 fanuary 1979)
ONE HUNDRED YEARS AGO I am pleased to find that the interest evoked in the bicycle correspondence denotes the importance of finding a means of rapid locomotion for the use of country practitioners, apart from the inseparable expense and annoyance in connection with horses. The subject is not only extremely interesting, but it is one of universal and daily application, whilst it involves a large pecuniary saving. Many practitioners have told me that their stable expenses are $£ 100$ and more per annum; and if this sum were saved and invested in good securities for the sustenance of old age, how much better would it be than in spending it in a vain and empty show of horseflesh, which, at the end of the year, shows nothing and benefits no one, whilst the bicycle or the Salvo quadricycle affords an easy and pleasant means of locomotion to an unlimited extent, and without a particle of annoyance. Mr Johnson's queries may be readily answered. The use of the Salvo quadricycle of Messrs Starley Brothers of Coventry, or other velocipede, to the utter exclusion of horse-flesh, must depend of course upon the practice, the neighbourhood, the roads, and the views of the practitioners. There can be no doubt that horses may be entirely dispensed with in many neighbourhoods, where the roads are good, tolerably level, and smooth. A moderate hill is easily surmounted, but up the very steep ones, I have got out and pushed the Salvo before me, which is most easily done, for the little power that it needs to do so, it bears a portion of the weight of the upper part of the body, and thus gives as well as takes. What is lost in this way is trebly or quadruply regained in returning, or in the next descent. Probably, in a whole journey, the up-hill work may not be a tenth or twentieth part of the whole. Good and smooth roads, to the exclusion of stones, are essential, but the way may be easily picked. If stones are one side, I go to the other, and occasionally go on the footpath; but stones are only on the roads for a very small part of the year. My own practice, which is a tolerably good one, extending to three or four miles from my house over moderately hilly roads, I worked entirely by Starley Brothers' Salvo quadricycle for three months without a horse. I travelled from ten to twenty miles a day, came home without being fatigued, and could easily have done as much more. I passed safely and easily over slippery roads and sheets of ice, whilst horses were slipping, sliding, and falling about me. The India-rubber tyres bite beautifully, even upon slides. Those three months were the busiest of the year, during last autumn. The labour of driving is nothing, except up a steep gradient. Even if a horse be kept, the Salvo is most convenient for afternoon, evening, and night work; it is ready in a moment, and thus the time of harnessing and getting ready a vehicle is saved; and whilst this is being done, many people may be dead. The Salvo may be used on a cold, dark and wet night, and lamps may be readily attached on to the bicycle; one or more- one on each wheel and one in front, or one alone. The machine, as I have said, would run readily upon the ice, but not well in snow if it were soft and deep; but frozen over and smooth, would be no impediment. It would be perfectly safe in a thin layer of snow. The wheels must be kept out of deep ruts, and not run upon stones of any kind. (British Medical fournal, 1879.) 